\title{
Acid and Enzymatic Hydrolysis of an Acidic Polysaccharide from Soy Sauce ${ }^{\dagger}$
}

\author{
Tadaaki KIKUCHI and Tamotsu YoKoTsUKA \\ Central Research Laboratories, Kikkoman Shoyu Co., Ltd., Noda-shi, Chiba-ken, Japan \\ Received July 4, 1972
}

\begin{abstract}
Mild acid hydrolysis of an acidic polysaccharide (APS-I) from soy sauce resulted in a degraded polysaccharide (DPS), the mixture of neutral sugar, D-galacturonic acid, its $a-1,4-$ linked homologous di- and trisaccharides, and acidic oligosaccharides containing residues of D-galacturonic acid and L-rhamnose. Besides the above-mentioned sugars, an aldobiouronic acid containing D-xylose moiety was also yielded in the enzymatic hydrolysates with a crude polysaccharidase preparation. However, only a $\beta-1$, 4-galactobiose was isolated from the lower molecular fraction of enzymatic digest of APS-I with a typical hemicellulase preparation. DPS containing $83 \%$ of D-galacturonic acid was able to be degraded by endo-polygalacturonase, but APS-I was not because of its highly branched structure. Partial structure of APS-I was discussed on the basis of these results. This consideration was also supported by the periodate oxidation study.
\end{abstract}

We have reported previously that two acidic polysaccharides containing large amount of D-galacturonic acid ( $\mathrm{ca} .50 \%$ ) existed in soy sauce. We have investigated also on their physico-chemical properties and concluded that these polysaccharides should be originated from soybean cell wall. ${ }^{1,2)}$ We now describe the results on the acid and enzymatic hydrolyses of one of the high molecular polysaccharides (APS-I, M. W. 320,000) for the structural investigation.

\section{MATERIALS AND METHODS}

Polysaccharide preparation. APS-I was prepared according to the reported method. ${ }^{11}$

Authentic oligosaccharides. 4-O- $\beta$-D-Galactopyranosyl-D-galactose ( $\beta$-1,4-galactobiose) was supplied by Dr. M. Morita of Tokyo University and 4-O- $(\alpha$-Dgalactopyranosyluronic acid)-D-galacturonic acid ( $a-1,4-$ galacturonobiose), $a$-1,4-galacturonotriose and the tetrasaccharide, D-galacturonic acid (Gal A) $1 \rightarrow 2$ L-rhamnose (Rha) $1 \rightarrow 4$ Gal A $1 \rightarrow 2$ Rha, by Dr. G. O. Aspinall of Trent University, Canada.

Enzyme preparations. A crude polysaccharidase preparation showing many kinds of polysaccharidedegrading enzyme activity besides endo-polygalacturo-

$\uparrow$ Studies on the Polysaccharides from Soy Sauce. Part II. nase (endo-PG) was obtained from koji-extract of Aspergillus japonicus 1744 by salting out with ammonium sulfate and following dialysis. ${ }^{3 !}$ Purified end-PG prepared from this crude polysaccharidase preparation was supplied by Mr. S. Ishii of this laboratories. ${ }^{31}$ A hemicellulase produced by Bacillus sp. was purchased from N.B.C. Co. It was dialysed against distilled water and freeze-dried before use.

General analyses. D-Galacturonic acid and Lrhamnose in the polysaccharides or in the oligosaccharides were estimated by the modified carbazole method ${ }^{4 !}$ and by cysteine sulfate method, ${ }^{5 !}$ respectively. The reducing power and the hydrolytic rate of polysaccharide (H.R.) were determined by the micro Willstätter-Schudel method. ${ }^{6 \nmid}$ Specific rotations $\left([a]_{\mathrm{D}}\right)$ of oligosaccharides were measured with JASCO automatic recording spectropolarimeter. The consumption of periodate and the release of formic acid in the periodate oxidation of the polysaccharide were assayed by the Fleury-Lange's method ${ }^{7}$ and by a titration method, respectively.

Determination of sugar composition. Analyses of neutral sugar compositions of the hydrolysates were performed by means of the automated liquid chromatography (JEOL, JLC-6AH Type; "Sugar Analyser"). Sample solution $(0.8 \mathrm{ml})$ was injected into the column $(0.8 \times 13.0 \mathrm{~cm})$ packed with an anion exchange resin (JEOL Resin IC-R-3, borate form), and eluted successively with three kinds of borate buffer (flow rate, $0.51 \mathrm{ml} / \mathrm{min}$ ). An orcinol-sulfuric acid reagent ${ }^{81}$ was used to detect sugars in the effluent: The eluent was mixed with concentrated sulfuric acid containing 
$0.08 \%$ of orcinol, heated at $95^{\circ} \mathrm{C}$ for $6 \mathrm{~min}$, cooled, and the absorbance at $440 \mathrm{~m} \mu$ was monitored and counted by the $\mathrm{KD}$ integrator. The amount of each sugar was calculated in comparison with the absorbance of the standard mixture.

Sugar compositions of polysaccharides were determined as follows: With $1 \mathrm{ml}$ of $1 \mathrm{~N}$-sulfuric acid, $10 \mathrm{mg}$ of polysaccharide was hydrolyzed at $100^{\circ} \mathrm{C}$. After $6 \mathrm{hr}$, the reaction mixture was neutralized with barium carbonate and then filtered. The filtrate was brought up to $20 \mathrm{ml}$. The solution was applied on the Sugar Analyser and neutral sugar composition was determined. The content of acidic sugar which was recognized as D-galacturonic acid in the paper chromatography was directly determined by carbazole method without acid hydrolysis, because the polyuronide was hard to be hydrolyzed quantitatively with acid.

Column chromatography. DEAE-Sephadex A-25 and Sephadex G-200 or G-75 (Pharmacia) were employed for ion exchange chromatography and for gel filtration, respectively. Cellulose powder (Toyo Kagaku) was used for the partition chromatography of neutral oligosaccharides. All the elution patterns were examined by the phenol sulfate method. ${ }^{9}$

Paper chromatography. Neutral sugars in hydrolysates were separated by ascending paper chromatography on Toyo No. 51A paper with solvent A (ethyl acetate-pyridine-water, 10:4:3 by vol.), and detected by the aniline-hydrogen-phthalate reagent. ${ }^{101} \mathrm{D}$ Galacturonic acid and acidic oligosaccharides were separated with solvent $B$ (ethyl acetate-acetic acidformic acid-water, 18:3:1:4 by vol.) or solvent $\mathrm{C}$ (ethyl acetate-acetic acid-formic acid-water, 18:9:3:4 by vol.). ${ }^{11}$ Acidic sugars were detected by the benzidine-TCA reagent. ${ }^{121}$ Thick paper, Toyo No. 526, was used for preparative paper chromatography.

\section{RESULTS}

\section{Sugar composition of APS-I}

The sugar composition was determined by the above-described method. The elution pattern of acid hydrolysate of APS-I on Sugar Analyser was shown in Fig. 1. APS-I was composed of $52.6 \%$ D-galacturonic acid, $12.1 \%$ L-rhamnose, $18.0 \%$ D-xylose, $14.7 \%$ D-galactose and $2.6 \%$ L-arabinose, as anhydro-sugars.

\section{Mild acid hydrolysis of APS-I}

APS-I $(500 \mathrm{mg}$ ) was dissolved in $50 \mathrm{ml}$ of $0.2 \mathrm{~N}$-sulfuric acid and hydrolyzed at $100^{\circ} \mathrm{C}$ for

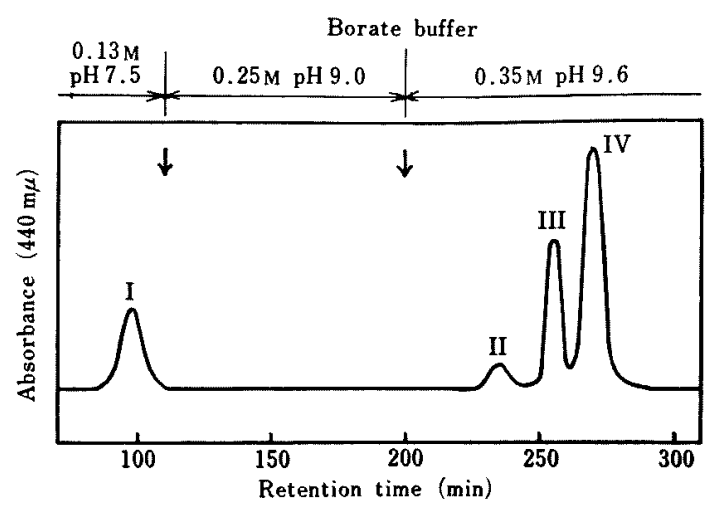

FIG. 1. Elution Pattern of the Neutral Sugars from APS-I on Sugar Analyser.

Conditions were described in Materials and Methods. (I) L-rhamnose, (II) L-arabinose, (III) D-galactose and (IV) D-xylose. $\rightarrow$, Buffer changing point.

$3 \mathrm{hr} \quad($ H.R. $=56.5 \%$ ). The hydrolysate was mixed with $150 \mathrm{ml}$ of acetone and centrifuged. Aqueous acetone $(75 \%)$ insoluble fraction, that is partially degraded polysaccharide (DPS), was washed with acetone and dried (Yield, $159 \mathrm{mg}$ ). DPS was composed of $83 \%$ D-galacturonic acid, 4\% L-rhamnose and $13 \%$ $\mathrm{D}$-xylose, as anhydro-sugars, but did not contain any amounts of D-galactose and L-arabinose.

Aqueous acetone soluble fraction was concentrated to $50 \mathrm{ml}$, neutralized with barium carbonate and filtered. Excess amounts of barium ions in the filtrate were eliminated with Dowex $50 \mathrm{~W}, \mathrm{X}-16$ (cation exchange resin). The neutralized solution was finally concentrated to $5 \mathrm{ml}$. This solution was subjected to gel filtration on a Sephadex G-75 column $(2.5 \times 110 \mathrm{~cm})$ and eluted with water. Lower molecular weight fractions (less than 1000) containing about $300 \mathrm{mg}$ of sugars were collected, concentrated to $10 \mathrm{ml}$, and chromatographed on DEAE-Sephadex A-25 (formate form). The elution with water gave the mixture of neutral sugar. The sugar analysis of this mixture resulted in L-rhamnose $(21 \mathrm{mg})$, D-xylose $(73 \mathrm{mg})$, D-galactose $(57 \mathrm{mg})$, Larabinose $(10 \mathrm{mg})$ and trace amounts of two neutral oligosaccharides. It seemed that Dgalactose and L-arabinose present in APS-I 


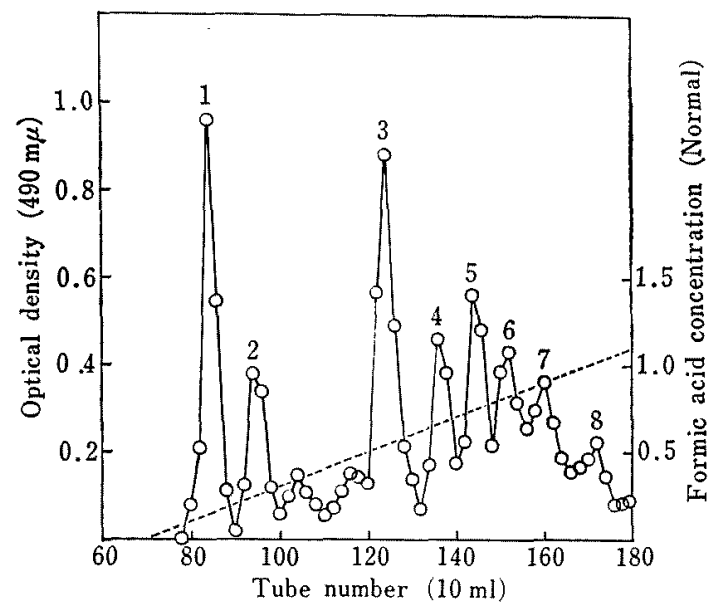

FIG. 2. Ion Exchange Chromatogram of Acidic Fraction in the Mild Acid Hydrolysate of APS-I.

Gradient elution was carried out with aqueous formic acid. Column: DEAE-Sephadex A-25 (formate form), $2.5 \times 40 \mathrm{~cm}$.

were quantitatively found in this neutral fraction. The neutral oligosaccharides containing in the mixture of neutral sugar were purified by partition chromatography on a cellulose powder column $(1 \times 35 \mathrm{~cm})$ with water-saturated butyl alcohol and by following thick paper chromatography. One of them formed only D-galactose on acid hydrolysis and was coincided with authentic $\beta$-1,4galactobiose on the paper chromatogram in solvent A. Another oligosaccharide was composed of D-galactose and L-arabinose (molar ratio, 2: 1).

After washing the column with water, acidic sugars were eluted by a gradient elution technique ( 0 to $1 \mathrm{~N}$-formic acid). The elution pattern was shown in Fig. 2. Each fraction was concentrated and further purified by thick paper chromatography. And then, they were characterized by means of paper chromatography, acid hydrolysis, colorimetrical analysis, and measurement of $[a]_{\mathrm{D}}$ in comparison with authentic samples. Acidic sugar 2, 3, 5 and 8 were coincided with authentic samples. Acidic sugar $1, R_{\mathrm{Ga} 1 \mathrm{~A}} 0.76$ with solvent $\mathrm{B},[a]_{\mathrm{D}}+84.7^{\circ}$. gave D-galacturonic acid and L-rhamnose (1:1) on hydrolysis. Since these results were agreed with the results obtained by G. O. Aspinall, ${ }^{13}$ this sugar was estimated to be 2-O-(D-galactopyranosyluronic acid)-L-rhamnose. Both acidic sugars 4 and 6 gave D-galacturonic acid and L-rhamnose (1:1) on hydrolysis and were thought to be tetrasaccharides from the result of analysis of reducing power. The results were summarized in Table I. The yields were estimated by colorimetric method.

\section{Enzymatic hydrolysis of APS-I}

Ten $\mathrm{mg}$ of APS-I $(5 \mathrm{ml})$ was incubated with the purified endo-PG or with the crude polysaccharidase, at $40^{\circ} \mathrm{C}$ for $24 \mathrm{hr}$. Each reaction mixture was subjected to gel filtration on Sephadex G-200 in order to compare the activities of those two enzymes (Fig. 3). It was considered that the hydrolysis with endo-PG did not yield any low molecular substances.

Table I Characterization of Acidic Sugars Isolated from the Mild Acid Hydrolysate of APS-I

\begin{tabular}{|c|c|c|c|c|c|}
\hline \multirow{2}{*}{$\begin{array}{l}\text { Acidic sugar } \\
\text { (Fig. 2) }\end{array}$} & \multirow{2}{*}{$\begin{array}{l}\text { Yield } \\
\text { (mg) }\end{array}$} & \multicolumn{2}{|c|}{$\mathrm{R}(\mathrm{Gal} \mathrm{A})$} & \multirow{2}{*}{$\begin{array}{l}\text { Sugars formed } \\
\text { on hydrolysis } \\
\text { (Molar Ratio) }\end{array}$} & \multirow{2}{*}{ Identical with } \\
\hline & & Solvent B & Solvent $\mathrm{C}$ & & \\
\hline 1 & 16 & 0.76 & 0.92 & Gal A, Rha $(1: 1)$ & $+84.7^{\circ}$ Gal A $1 \rightarrow 2$ Rha \\
\hline 2 & 12 & 1.00 & 1.00 & & ${ }^{*} \mathrm{D}-$ Galacturonic acid \\
\hline 3 & 34 & 0.14 & 0.59 & Gal A, Rha $(1: 1)$ & $+86.3^{\circ}$ Gal A $1 \rightarrow 2$ Rha $1 \rightarrow 4$ \\
\hline 4 & & 0.04 & 0.15 & Gal A, Rha $(1: 1)$ & \\
\hline 5 & 28 & 0.19 & 0.48 & Gal A & 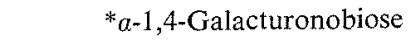 \\
\hline 6 & & 0.10 & & Gal A, Rha $(1: 1)$ & \\
\hline 7 & & 0.11 & & Gal A, Rha (2:1) & \\
\hline 8 & 15 & 0.06 & 0.21 & Gal A & ${ }^{*} a-1,4-$ Galacturonotriose \\
\hline
\end{tabular}




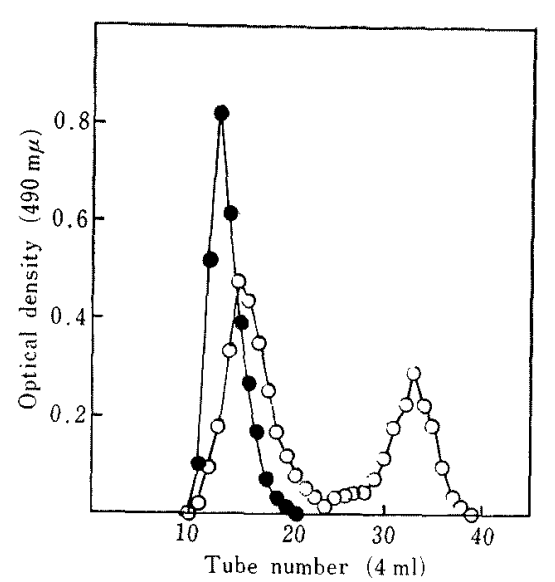

FIG. 3. Elution Patterns of the Enzymatic Hydrolysates of APS-I on a Sephadex G-200 Column.

One $\mathrm{ml}$ of the reaction mixture was mixed with an equal volume of $0.4 \mathrm{M} \mathrm{NaCl}$ and applied on to a column $(1.5 \times 90 \mathrm{~cm})$. Elution was performed with $0.2 \mathrm{M} \mathrm{NaCl}$. - with purified endo-PG, O-O with crude polysaccharidase.

Consequently, it seemed that APS-I could not be attacked, at least, by endo-PG alone. On the other hand, it was recognized that the crude polysaccharidase divided APS-I into two different molecular weight components and therefore, large amount of APS-I ( $1 \mathrm{~g}$ in $80 \mathrm{ml}$ of water) was incubated with $20 \mathrm{mg}$ of the crude polysaccharidase at $40^{\circ} \mathrm{C}$ for $60 \mathrm{hr}$ $($ H.R. $=17.5 \%)$. Aqueous acetone $(75 \%)$ soluble fraction of the reaction mixture was subjected to the ion exchange chromatography in the same manner as on the mild acid hydrolysate. The neutral fraction eluted with water contained L-rhamnose (18 mg), D-xylose ( $7 \mathrm{mg}$ ), D-galactose (44 $\mathrm{mg}$ ) and L-arabinose $(6 \mathrm{mg})$. Consequently, it was considered that $\mathrm{D}$ xyloside linkage was hard to be hydrolyzed with the enzyme. Then, 6 acidic sugars, namely, Gal A $1 \rightarrow 2$ Rha $(8 \mathrm{mg})$, unknown oligosaccharide (14 mg), D-galacturonic acid $(22 \mathrm{mg}$ ), Gal $A \quad 1 \rightarrow 2$ Rha $1 \rightarrow 4$ Gal A $1 \rightarrow 2$ Rha $(16 \mathrm{mg}), a-1$,4-galacturonobiose $(7 \mathrm{mg})$ and $a$-1,4-galacturonotriose $(2 \mathrm{mg})$, were gradiently eluted with 0 to $1 \mathrm{~N}$ formic acid from a DEAE-Sephadex column. These sugars were also found in the case of mild acid hydrolysis, with the exception of the unknown sugar, which, $\mathrm{R}_{\mathrm{Gal}_{\mathrm{A}}} 0.49$ with solvent $\mathrm{B},[a]_{\mathrm{D}}+26.7^{\circ}$, contained $\mathrm{D}$-galacturonic acid and $D$-xylose residue in the molar ratio of $1: 1$.

On the other hand, $20 \mathrm{mg}$ of APS-I in $4 \mathrm{ml}$ of $0.5 \mathrm{M}$-acetate buffer ( $\mathrm{pH} \mathrm{6.0)}$ was incubated with $1 \mathrm{mg}$ of the hemicellulase preparation for $24 \mathrm{hr}$ at $40^{\circ} \mathrm{C}$. Aqueous acetone $(75 \%)$ soluble fraction obtained from the reaction mixture was composed of only a $\beta$-1, 4-galactobiose and none of other neutral or acidic sugars were detected on the paper chromatogram.

\section{Enzymatic hydrolysis of DPS}

DPS (50 mg) in $5 \mathrm{ml}$ of water was incubated with endo-PG at $40^{\circ} \mathrm{C}$ for $24 \mathrm{hr}$. The reaction mixture was added with triple volume of acetone, and aqueous acetone soluble fraction was concentrated. This fraction was composed of D-galacturonic acid, $a$-1,4-galacturonobiose and the aldobiouronic acid containing D-xylose in its molecule. The last-named product was also isolated from the enzymatic hydrolysates of APS-I with the crude polysaccharidase. In this case, none of neutral sugar was detected.

\section{Periodate oxidation of $A P S-I$}

APS-I $(20 \mathrm{mg})$ dissolved in $20 \mathrm{ml}$ of water was oxidized with $0.4 \mathrm{~mm}$ sodium metaperiodate $(20 \mathrm{ml})$ at $5^{\circ} \mathrm{C}$ in the dark. At suitable intervals, the consumption of periodate and the release of formic acid was determined. After $96 \mathrm{hr}$, the reaction was finished and 0.86 mole of periodate was consumed and 0.21 mole of formic acid was released per one mole of average anhydro-sugar residue (M.W. 159) which was calculated from the sugar composition of APS-I. After the elimination of excess metaperiodate with ethylene glycol, the mixture was dialysed. The oxo-polysaccharide obtained was hydrolyzed with $1 \mathrm{~N}^{\mathrm{H}_{2} \mathrm{SO}_{4}}$ at $100^{\circ} \mathrm{C}$ for $4 \mathrm{hr}$. The paper chromatography (solvent $A$ and $B$ ) revealed the presence of D-galacturonic acid, D-galactose and trace amount of L-rhamnose in the hydrolysate. 


\section{DISCUSSION}

In the previous report, ${ }^{11}$ APS-I, a high molecular acidic polysaccharide, was purified from soy sauce and its physico-chemical properties were investigated. This polysaccharide contained D-galacturonic acid, L-rhamnose, D-xylose, D-galactose and L-arabinose. The molar ratios of these sugars were calculated to be 15:4:7:5:1, approximately. Some informations of the structural modes of the sugar residues in APS-I were provided by both acid and enzymatic hydrolyses.

Partial acid hydrolysis of APS-I gave a mixture of a partially degraded polysaccharide (DPS) and low molecular weight sugars. DPS contained D-galacturonic acid, L-rhamnose and $\mathrm{D}$-xylose (approximate molar ratio, $16: 1: 3$ ), and about a half part of D-galacturonic acid residue in APS-I remained in DPS. Accordingly, DPS is considered to be one of the frame structure of APS-I. When DPS was incubated with the purified endo-PG, D-galacturonic acid, a-1,4-galacturonobiose and an aldobiouronic acid (I) composed of D-galacturonic acid and D-xylose were released. This fact suggests that DPS is mainly constituted with $a$-1,4-linked D-galacturonic acid residues, and $\mathrm{D}$-xylose residue is attached as side chain.

Another product of mild acid hydrolysis, low molecular weight sugars, was divided into neutral and acidic fractions. Neutral fraction contained L-rhamnose, D-xylose, D-galactose and L-arabinose. Trace amounts of two oligosaccharides identified to be $\beta$-1,4-galactobiose and a trisaccharide composed of $D$ galactose and L-arabinose (molar ratio, 2:1) were also found in this fraction. $\beta$-1,4-Galactobiose was a sole low molecular product when APS-I was incubated with the hemicellulase. These results suggest the possibility that $D$ galactose may form $\beta$-1,4-linked polymer and L-arabinose residue may be in the side chain of the above-stated $\beta$-1,4-linked $D$-galactose chain rather than that of $a$-1,4-linked Dgalacturonic acid chain. These suggestions are also supported by the fact that D-galactose and L-arabinose residues are not found in DPS or acidic oligosaccharides. Such galactan chain attached with L-arabinose was previously observed by one of the authors (T.K.) as an intramolecular accompanying chain in the acidic polysaccharide of soybean cell wall. ${ }^{14}$ )

In the acidic fraction, several kinds of acidic sugar, D-galacturonic acid, a-1,4-galacturonobiose and -triose, 2-O-(D-galactopyranosyluronic acid)-L-rhamnose (II, Gal A $1 \rightarrow 2$ Rha), the tetrasaccharide, Gal A $1-2$ Rha $1 \rightarrow 4$ Gal A $1 \rightarrow 2$ Rha (III), and some heterooligosaccharides composed of D-galacturonic acid and L-rhamnose, were recognized. The presence of these acidic sugars formed by mild acid hydrolysis demonstrates that the main chain of APS-I is also composed of Gal A $1 \rightarrow 2$ Rha unit besides $a-1,4$-linked Dgalacturonic acid unit. Moreover, the fact that II and III was produced from APS-I together with the production of DPS which was mainly composed of $a$-1,4-polygalacturonide, suggests a portion of the main chain is probably constituted with repeated Gal A $1 \rightarrow 2$ Rha unit. The above-mentioned possible structure of APS-I is supported by the enzymatic hydrolysis. However, besides the acidic sugars obtained by acid hydrolysis, I was released by the crude polysaccharidase. Consequently, it is possible to suppose as in the case of DPS, that D-xylose residue may attach to D-galacturonic acid in the main chain, although it is still impossible to state whether the side chain is 2-O- or 3-O-substituted. This complicated structure resembles that of the acidic polysaccharides in soybean cotyledon. ${ }^{13)}$

APS-I was unable to be degraded by endoPG, but it was degraded by the crude polysaccharidase which contained many other polysaccharide-degrading enzyme activities besides endo-PG (Fig. 3). On the other hand, DPS which contains less amount of side chain was degraded by endo-PG alone. These results suggest that APS-I has a highly branched structure and the activity of the endo-PG is repressed by the existence of neutral sugars. 


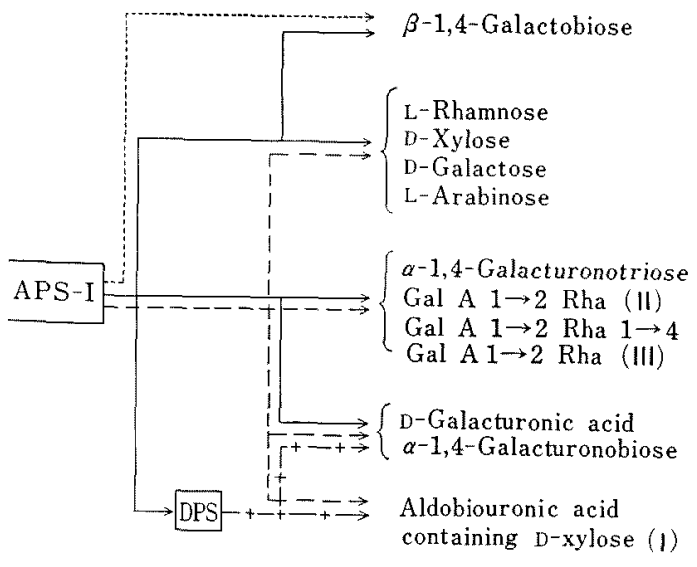

FIG. 4. Acid and Enzymatic Hydrolyses of APS-I.

- Mild acid, ---- Crude polysaccharidase, +-+ , Endo--PG, ...... Hemicellulase.

The results of acid and enzymatic hydrolysis was summarized in Fig. 4. From the present results, a possible structure of APS-I is proposed as follows: The frame structure of APS-I is composed of $a-1,4-$ linked Dgalacturonide long chain and of 2-O-substituted L-rhamnose residue which forms Gal A $1 \rightarrow 2$ Rha unit. D-Xylose is attached to Dgalacturonic acid as side chain. D-Galactose forms $\beta$-1,4-polymer and may be attached to main chain though its detailed structure is unknown. L-Arabinose residue is in the side chain of D-galactoside polymer.

This branched structure was also supported by periodate oxidation. As shown in Table II, the values of consumed periodate and of released formic acid agreed with those calculated on the basis of the possible structure of APS-I by a rule of periodate oxidation of polysaccharide. ${ }^{15}$ i Moreover, the existence of both D-galacturonic acid and D-galactose in the hydrolysate of periodate oxidation product gave some hints about the branching points of APS-I. However, from the result of periodate oxidation, it is probable that the side chains are partially attached also to I-rhamnose residue.

The basic structure of APS-I appears to be simpler than that of the acidic polysaccharides in soybean cell wall. However, D-
Table II. Calculated or Found Values of Consumed Periodate and Released Formic Acid in Periodate OXIDATION OF APS-I

\begin{tabular}{|c|c|c|c|}
\hline \multirow[b]{2}{*}{ Sugar residue } & \multirow[b]{2}{*}{$\begin{array}{l}\text { Molecular } \\
\text { ratio }\end{array}$} & \multicolumn{2}{|c|}{ Calculated value } \\
\hline & & $\begin{array}{l}\text { Peri- } \\
\text { odate }\end{array}$ & $\begin{array}{l}\text { Formic } \\
\text { acid }\end{array}$ \\
\hline $\begin{array}{l}\text { 4-O-D-Galacturonic } \\
\text { acid }\end{array}$ & 7 mole & 7 mole & 0 mole \\
\hline $\begin{array}{l}\text { 4- and 2- or 3-O- } \\
\text { D-Galacturonic } \\
\text { acid }^{a 1}\end{array}$ & 8 & 0 & 0 \\
\hline 2-O-L-Rhamnose & 4 & 4 & 0 \\
\hline D-Xylose $e^{b}$ & 7 & 14 & 7 \\
\hline 4-O-D-Galactose & 4 & 4 & 0 \\
\hline $\begin{array}{l}\text { 4- and 2- or 3-O- } \\
\text { D-Galactose }\end{array}$ & 1 & 0 & 0 \\
\hline L-Arabinose ${ }^{b /}$ & 1 & 1 & 0 \\
\hline Total & 32 & 30 & 7 \\
\hline \multirow{2}{*}{$\begin{array}{l}\text { Moles per one mole } \\
\text { of average anhydro- } \\
\text { sugar }\end{array}$} & \multirow{2}{*}{$\begin{array}{l}\text { Calcu- } \\
\text { lated } \\
\text { Found }\end{array}$} & 0.94 & 0.22 \\
\hline & & 0.86 & 0.21 \\
\hline
\end{tabular}

a) Sugar residue in brancing points.

$b$ Side chain.

galacturonic acid content of the former is much more than that of the latter. This suggests that the acidic polysaccharides of soybean cell wall may be modified through the steam-cooking or the enzymatic process during the fermentation of soy sauce.

We are starting the investigation on more detailed structure of APS-I by means of methylation and of Smith degradation.

Acknowledgements. The authors wish to express their sincerest thanks to Prof. Dr. M. Fujimaki of Tokyo University for his kind guidance and encouragement throughout this work. Thanks are also due to Dr. G. O. Aspinall and Dr. M. Morita for their gifts of authentic oligosaccharides; to Mr. S. Ishii, Dr. Y. Ozawa and Dr. K. Hayashi for their technical advices; and to Dr. H. Sugimoto for his helpful discussion and encouragement.

\section{REFERENCES}

1) T. Kikuchi and T. Yokotsuka, Agr. Biol. Chem., 36, 544 (1972).

2) T. Kikuchi, S. Ishii, D. Fukushima and $T$. Yokotsuka, Nippon Nogeikagaku Kaishi, 45, 235 (1971).

3) S. Ishii and T. Yokotsuka, Agr. Biol. Chem,, 36, 1885 (1972). 
4) T. Bitter and H. M. Muir, Anal. Biochem., 4, 330 (1962).

5) Z. Dishe and L. B. Shettles, J. Biol. Chem., 175, 595 (1948).

6) C. Hatanaka, Nippon Nogeikagaku Kaishi, 41, 448 (1967).

7) P. F. Fleury and J. Lange, J. Pharm. Chim., 17, 107 (1933).

8) R. B. Kesler, Anal. Chem., 39, 1416 (1967).

9) M. Dubois, K. A. Gillis, J. K. Hamilton, P. A. Rebers and F. Smith, ibid., 28, 350 (1956).

10) C. M. Wilson, ibid., 31, 1199 (1959).
11) G. O. Aspinall, K. Hunt and I. M. Morrison, J. Chem. Soc., 1966, 1945.

12) J. S. D. Bacon and J. Edelman, Biochem. $J$., 48, 114 (1951).

13) G. O. Aspinall, I. W. Cottrell, S. V. Egan, I. M. Morrison and J. N. C. Whyte, J. Chem. Soc., 1967, 1071.

14) T. Kikuchi, Nippon Nogeikagaku Kaishi, 46, 405 (1972).

15) J. M. Bobbit, Advan. Carbohydrate Chem., 11, 1 (1956). 